\title{
NRAMP1 Polymorphisms like Susceptibility Marker in Mexican Focus of Cutaneous Leishmaniasis
}

\author{
Mirsha Pamela Hernández-Rivera, ${ }^{1}$ Alicia Ramírez-Ramírez, ${ }^{2}$ Adelaido Chiñas-Pérez, ${ }^{3}$ \\ Amalia Monroy-Ostria, ${ }^{1}$ Mario Eugenio Cancino-Díaz, ${ }^{1}$ and Omar Hernández-Montes ${ }^{1}$ \\ ${ }^{1}$ Departamento de Inmunología, Escuela Nacional de Ciencias Biológicas, IPN, Carpio y Plan de Ayala, 11340 Mexico City, Mexico \\ ${ }^{2}$ Departamento de Infectología e Inmunología, Instituto Nacional de Perinatología, Montes Urales 800, 11000 Mexico City, Mexico \\ ${ }^{3}$ H. Ayuntamiento de Calakmul, Halaltun, 24640 Xpujil, CAM, Mexico
}

Correspondence should be addressed to Omar Hernández-Montes; ohm2000@hotmail.com

Received 6 August 2016; Accepted 22 September 2016

Academic Editor: Charles Spencer

Copyright (C) 2016 Mirsha Pamela Hernández-Rivera et al. This is an open access article distributed under the Creative Commons Attribution License, which permits unrestricted use, distribution, and reproduction in any medium, provided the original work is properly cited.

\begin{abstract}
Cutaneous leishmaniasis (CL) is endemic in Campeche state, Mexico. Host and parasite factors are involved in the establishment and development of CL. Host factors include immune response and genetic background. NRAMP1 (Natural Resistance Associated Macrophage Protein 1) is important in innate immunity. Polymorphisms in NRAMP1 have been associated with susceptibility or resistance to infectious and autoimmune diseases. To study the association of NRAMP1 mutations with CL in patients from Calakmul, Campeche, samples from 115 CL patients and 69 samples of healthy people from the same area were evaluated. Five regions in NRAMP1 were amplified and digested, looking for mutations in the promoter region $(-524 \mathrm{G} / \mathrm{C})$, exon 3 (274C/T), exon $8(823 \mathrm{C} 7 \mathrm{~T})$, and exon $15(\mathrm{G} / \mathrm{A})$ and deletion of $4 \mathrm{bp}$ in the $3^{\prime} \mathrm{UTR}$ region. We found a statistical association between polymorphisms in $3^{\prime} \mathrm{UTR}$ region and exon 8 and CL $\left[\chi^{2}=13.26 ; p<0.05 ; \mathrm{OR}=17.00\right.$; IC of $95 \%$ (2.24-128.99)]. Some patients who needed more than 40 doses of Glucantime ${ }^{\circledR}$ to heal injuries presented mutations in exons 3, 8, and 15 . Multiple or ear lesions were not associated with NRAMP1 polymorphism.
\end{abstract}

\section{Introduction}

Leishmaniasis is zoonotic disease, caused by different species of the genus Leishmania, protozoa transmitted to human and animal reservoirs by the bite of infected phlebotomine sandflies (genus Lutzomyia, in the new world) [1-3]. Leishmaniasis is endemic in the most tropical regions of the world; furthermore several factors like climate change, urbanization, deforestation, increased travel for tourist and work-related reasons, immigrations from endemic countries, and military operations can lead to an increase in risk of contracting the diseases in new areas [4]. In Mexico, four clinical forms of leishmaniasis are found, localized cutaneous leishmaniasis (LCL), diffuse cutaneous leishmaniasis (DCL), mucocutaneous leishmaniasis (ML) caused by $L$. (L.) mexicana, and visceral leishmaniasis (VL) [5, 6]; furthermore there are reports of $L$. (V.) braziliensis [5, 7] and $L$. (L.) chagasi [8]. The sylvatic region of the Yucatan Peninsula is an endemic focus of leishmaniasis; most of the recorded cases are LCL with few well limited ulcers located mainly on the ear, head, neck, and upper limb [9]. DCL is characterized by a large number of nodular skin lesions and MCL is a severe form with inflammations with progressive destruction of the mucocutaneous tissues. Both forms are rare in Mexico.

In murine models, the earliest phases and resistance to the infection with different species of Mycobacterium and other intracellular microorganisms like Leishmania are under control of NRAMP1 (Natural Resistance Associated Macrophage Protein 1) encoded by NRAMP1 gene, previously called Bcg/Lsh/Ity (Mycobacterium bovis BCG, Leishmania donovani, and Salmonella typhimurium) which has $88 \%$ identity with the human formerly called NRAMP1 $[10,11]$ and now called SLC11A1 (solute carrier family 11 member 1 protein). NRAMP1 is expressed in the membrane fraction in late endosome and lysosomes in macrophages and polymorphonuclear leukocytes as a 90-100 KDa phosphoglycoprotein 
[12] and acts as a pH-dependent divalent cation carrier. This protein has been found in close association with natural resistance to infection with some intracellular pathogens, which plays a critical role in early innate macrophage responses to intracellular infection. Polymorphisms of human SLC11A1 are associated with susceptibility to several inflammatory autoimmune disorders, as well as infectious diseases in African and Asian populations, including leprosy, tuberculosis, visceral leishmaniasis, and human immunodeficiency virus [12, 13]. Polymorphisms have also been suggested to modulate expression or alter the functional capacity of SLC11A1 to transport divalent cations, respectively [14]. In the case of leishmaniasis diseases, polymorphism of SLC11A1 coupled with the expression of other genes has been associated with susceptibility to some forms of this disease in a specific Mexican endemic area [15] and specifically with CL in Brazil [16] and VL in Sudan [17] and Morocco [18].

Over five years of work in Campeche state, located in the Yucatan Peninsula, specifically in the municipality of Calakmul, endemic area for LCL, we have observed different behaviors of the clinical expression of CL and we found people living in this area who have never developed any form of CL to people who present with the disease more than once, all of them living under the same conditions. On the other hand, we have noticed that there is a variable response to Glucantime [19]. Some patients resolved CL with 15 to 20 doses and others required 40 to 100 doses to get the same effect. The host genetic background and immune response are important in the evolution of the infection. The purpose of this study was to evaluate the correlation between susceptibility or resistance to leishmaniasis with polymorphisms in NRAMP1 in patients with CL from Calakmul, Campeche.

The polymorphisms analyzed in this research were four single nucleotide polymorphisms (SNPs) identified in the promotor region $(-524 \mathrm{G} / \mathrm{C})$, in exon $3(274 \mathrm{C} / \mathrm{T})$, in exon 8 $(823 \mathrm{C} / \mathrm{T})$, and in exon $15(\mathrm{D} 543 \mathrm{~N})$ and one deletion in the $3^{\prime}$ UTR region $(1729+55 \mathrm{del} 4)$. All of them related to resistance to intracellular microorganisms in humans.

\section{Materials and Methods}

2.1. Blood Samples. Blood samples were collected in the municipality of Calakmul, Campeche, from 115 patients with clinical and parasitologic diagnosis of CL. Patients, male or female over 10 years old, were included. Leishmania species was identified by PCR amplification. Leishmania (L.) mexicana was the causative agent in most of the cases, with few caused by Leishmania (V.) braziliensis. All the cases in the current study responded to antileishmanial therapy with Glucantime. Control group was defined as healthy individuals ( $n=69$ ), who never had the disease, are without scars or injuries related to CL, and are male or female over 10 years old. Each participant signed a letter of informed consent, and inclusion of young children consent was obtained from parents or guardians. The research was approved by the ethical committee of the Escuela Nacional de Ciencias Biológicas from Instituto Politécnico Nacional and with authorization from the municipality of Calakmul, Campeche, with the participation of its Public Health Department, in agreement with
TABle 1: Primers used in this study.

\begin{tabular}{ll}
\hline Polymorphisms & Primers \\
\hline -524G/C & $5^{\prime}$-AAC AAC TCT GAG AAG GGA CA-3' \\
& $5^{\prime}$-TGT GCC CCA CAA CAC ATC TG-3' \\
$274 \mathrm{C} / \mathrm{T}$ & $5^{\prime}$-TGC CAC CAT CCC TAT ACC CAG-3' \\
& $5^{\prime}$-TCT CGA AAG TGT CCC ACT CAG -3' \\
$823 \mathrm{C} / \mathrm{T}$ & $5^{\prime}$-CTT GTC CTG ACC AGG CTC CT-3 \\
& $5^{\prime}$-CAT GGC TCC GAC TGA GTG AG-3' \\
D543N & $5^{\prime}$-GCA TCT CCC CAA TTC ATG GT-3' \\
$1729+55$ del 4 & $5^{\prime}$-AAC TGT CCC ACT CTA TCC TG-3' \\
\hline
\end{tabular}

the International Ethic Guidelines for Biomedical Research Involving Human Subjects and the Norma Oficial Mexicana de Salud: NOM-003-SSA 2-1993, for sampling blood from human beings for diagnosis and therapeutics. The study was registered in the "Libro de Actas del Cabildo" with date May $24,2002$.

2.2. DNA Extraction. DNA was obtained from venous blood samples, and DNA extraction was performed using the Gentra Puregene Kit (QIAGEN, Germany).

2.3. NRAMP1 Genotyping. Polymerase Chain ReactionRestriction Fragment Length Polymorphisms (PCR-RFLP) methods were used for genotyping four polymorphic regions (SNPs) of the NRAMP1 gene: substitution $-524 \mathrm{G} / \mathrm{C}$ in the promoter region, substitution $274 \mathrm{C} / \mathrm{T}$ in exon 3 , substitution $823 \mathrm{C} / \mathrm{T}$ in exon 8, amino acid substitution D543N G/A in exon 15, and one deletion $1729+55$ del 4 (TGTG) in the $3^{\prime}$ untranslated region (UTR). The methodology used was as described by Saiki and colleagues [20], using sequence specific oligonucleotides which were previously described (Table 1) [21-24] and performed in a Gene Amp PCR Systems 9700 thermocycler (Applied Biosystems), using $0.20 \mathrm{mM}$ of each dNTP, $50 \mathrm{pM}$ of each primer, $1.5 \mathrm{mM} \mathrm{MgCl}_{2}, 10 \mathrm{mM}$ Tris $\mathrm{pH} 8.4,50 \mathrm{mM} \mathrm{KCl}, 0.01 \%$ gelatin, and $1.25 \mathrm{U}$ of Taq polymerase (Invitrogen Life Technologies, CA, USA) in a $50 \mu \mathrm{L}$ reaction. The PCR conditions for the five polymorphisms were the same: one cycle of $96^{\circ} \mathrm{C}$ for $5 \mathrm{~min}, 60^{\circ} \mathrm{C}$ for $60 \mathrm{sec}$, and $72^{\circ} \mathrm{C}$ for $60 \mathrm{sec}$, followed by 35 cycles of denaturation at $93^{\circ} \mathrm{C}$ during $45 \mathrm{sec}$, annealing at $60^{\circ} \mathrm{C}$ for $60 \mathrm{sec}$ and extension at $72^{\circ} \mathrm{C}$ for $60 \mathrm{sec}$ and one elongation step at $72^{\circ} \mathrm{C}$ for $10 \mathrm{~min}$ utes. The amplicons were analyzed by horizontal electrophoresis on $2 \%$ agarosa gels in TBE buffer at $110 \mathrm{~V}$ for 1 hour. The gels were stained with ethidium bromide $(1 \mathrm{mg} / \mu \mathrm{L})$ and visualized using UV illumination system. RFLP were made using $10 \mu \mathrm{L}$ of amplicon in $20 \mu \mathrm{L}$ of reaction with one of the following restriction endonucleases: Ava II, Fok I, Hinf I, Mnl $I$, and Nar I for exon 15, $3^{\prime}$ UTR, promoter region, exon 3, and exon 8 amplicons, respectively. According to the manufacturer's instructions (New England Biolabs and Invitrogen Life Technologies), restriction enzyme digestion products were resolved using a vertical electrophoresis, on $8 \%$ acrylamide gel, and were stained with ethidium bromide $(1 \mathrm{mg} / \mu \mathrm{L})$ and visualized under UV light. 
TABLE 2: Details of the polymorphisms genotyped and identified by PCR-RFLP in NRAMP1.

\begin{tabular}{|c|c|c|c|c|}
\hline Polymorphisms & Localization & PCR product size & Restriction enzyme & Restriction enzyme products \\
\hline$-524 \mathrm{G} / \mathrm{C}$ & Promoter region & $585 \mathrm{bp}$ & Hinf I & $\begin{array}{c}\text { Allele } 1 \text { (G): } 43(2), 61,62,79,297 \mathrm{bp} \\
\text { Allele } 2 \text { (C): 43, 61, 79, 105, } 297 \mathrm{bp} \\
\text { G/C: 43, 61, 62, 79, 105, } 297 \mathrm{bp}\end{array}$ \\
\hline $274 \mathrm{C} / \mathrm{T}$ & Exon 3 & $216 \mathrm{bp}$ & Mnl I & $\begin{array}{l}\text { Allele } 1(\mathrm{C}): 12,37,65,102 \mathrm{bp} \\
\text { Allele } 2(\mathrm{~T}): 12,37,167 \mathrm{bp} \\
\text { C/T: } 12,37,65,102,167 \mathrm{bp} \\
\end{array}$ \\
\hline $823 \mathrm{C} / \mathrm{T}$ & Exon 8 & $234 \mathrm{bp}$ & Nar I & $\begin{array}{l}\text { Allele } 1 \text { (C): 99, } 135 \mathrm{bp} \\
\text { Allele } 2(\mathrm{~T}): 234 \mathrm{bp} \\
\text { C/T: } 99,135,234 \mathrm{bp} \\
\end{array}$ \\
\hline D543N & Exon 15 & $240 / 244 \mathrm{bp}$ & Ava II & $\begin{array}{c}\text { Allele } 1 \text { (Asp): 39, 79, 122/126 bp } \\
\text { Allele } 2 \text { (Asn): 39, 201/205 bp } \\
\text { Asp/Asn: 39, 79, 122/126, 201/205 bp }\end{array}$ \\
\hline $1729+55 \operatorname{del} 4$ & $3^{\prime} \mathrm{UTR}$ & $240 / 244$ bp & Fok $I$ & $\begin{array}{l}\text { Allele } 1 \text { (+TGTG): 33, } 211 \text { bp } \\
\text { Allele } 2(- \text { TGTG): } 240 \\
\quad+/-: 33,211,240\end{array}$ \\
\hline
\end{tabular}

2.4. Statistical Analysis. Frequency in genotype differences between patients and control subjects was examined using the Chi-square test with two degrees of freedom and was considered statistically significant when $p<0.05$. Further the previous analysis included odds ratio test, with a confidence interval of $95 \%$ to quantitatively assess the degree of association between polymorphisms in NRAMP1 gene and CL.

\section{Results}

3.1. NRAMP1 Polymorphisms. -524G/C; 274C/T; 823C/T; D543NG/A; and 1729 + 55del4 (TGTG) were evaluated by PCR-RFLP. Table 2 shows details of the polymorphisms genotyped from 115 blood samples from patients with CL and 69 samples healthy controls, collected in the Calakmul municipality in Campeche state, Mexico.

$823 \mathrm{C} / \mathrm{T}$ polymorphism was significantly associated with CL infection $(p<0.05)$, a silent nucleotide substitution $(\mathrm{C}$ to $\mathrm{T})$. The genotype $\mathrm{C} / \mathrm{T}$ and the minor allele $(\mathrm{T} / \mathrm{T})$ were expressed in CL group while its expression is absent in the control group. This mutation was found related to the presence of the CL $(p<0.05$, OR $[\mathrm{CI}=95 \%]=17.0)$ (Table 3$)$. $3^{\prime}$ UTR $(1729+55$ del 4$)$ was significantly associated with infection of CL either; the mutated alleles del/del and TGTG+/del are present in CL patients and in minor proportion in the control group $(p<0.05$, OR $[\mathrm{CI}=95 \%]=2.76)$.

In this study no association was detected with other polymorphisms analyzed when comparing patients with control group.

3.2. Polymorphism in NRAMP1 and Requirements of Glucantime Doses. The potential relationship between polymorphisms and requiring of higher dosages of Glucantime than the average dose of 25 ampules used in CL patients of the same region [25] was evaluated in this study. Association with polymorphism 274C/T in exon 3 of NRAMP1 was found. 11 of 13 samples presented the mutated alleles (Table 4), and two samples had the original allele. Association with polymorphisms $823 \mathrm{C} / \mathrm{T}$ in exon 8 and D543NG/A in exon 15 of NRAMP1 was also found. Only 4 samples for exon 8 and 3 samples for exon 15 had mutated allele in homozygous way. It was not finding the heterozygous mutation in both cases. Analysis in the $3^{\prime}$ UTR region shows no association. The correlation between the number of lesions and polymorphisms was also analyzed (results not shown) but no significant association was found.

\section{Discussion}

Several studies have established that NRAMP1 is a gene coding for an important regulatory element in the tracks of macrophages activation and differentiation $[24,26]$. NRAMP1 gene has been associated with susceptibility and resistance to diseases caused by intracellular pathogens, such as the protozoan Leishmania. In this study, we analyzed five polymorphic regions of NRAMP1 in samples of patients with CL form and control people (without CL), four single nucleotide polymorphisms, and one deletion of four nucleotides in the $3^{\prime}$ UTR region, in order to know their effect on the risk to develop CL after infection in an endemic area. Bellamy [25] has suggested a strong relationship between some polymorphisms in NRAMP1 ( $5^{\prime}(\mathrm{CA}) \mathrm{n}, \mathrm{INT} 4, \mathrm{D} 543 \mathrm{~N}$, and deletion in $3^{\prime} \mathrm{UTR}$ region) and the increased risk of acquiring tuberculosis in west area of Africa [26, 27]. However, other studies which involved patients from Korea, Japan, Brazil, and Denmark suggested no association between polymorphisms in NRAMP1 and the risk of acquiring tuberculosis. Although it is the same disease, the results are different because the patients belong to different ethnic groups with different genetic background and clinical status [27]. Similar results were found with other diseases caused by intracellular pathogens in different populations. In Leishmania infection, NRAMP1 polymorphisms could play an important role in the pathology of the disease, referring specifically to CL and VL susceptibility in an endemic area in Chiapas state, Mexico [15]. Therefore, we consider the study of the polymorphisms present in three exons in NRAMP1 relevant if they could have high possibility of affecting the NRAMP1 protein function. In addition, the promoter region plays a decisive role in the 
TABLE 3: Genotype frequency of the NRAMP1 polymorphisms.

\begin{tabular}{|c|c|c|c|c|}
\hline Genotypes & CL (\%) & Controls (\%) & $\chi^{2}$ value & OR $(95 \% \mathrm{CI})$ \\
\hline Promoter region -524 & & & & \\
\hline Promoter region $-524 \mathrm{G} / \mathrm{G}$ & $115(100)$ & $69(100)$ & \multirow{3}{*}{\multicolumn{2}{|c|}{ Not statistically significant }} \\
\hline Promoter region -524 G/C & 0 & 0 & & \\
\hline Promoter region $-524 \mathrm{C} / \mathrm{C}$ & 0 & 0 & & \\
\hline \multicolumn{5}{|l|}{ Exon 3274} \\
\hline Exon $3274 \mathrm{C} / \mathrm{C}$ & $48(41.73)$ & $35(50.72)$ & \multirow{3}{*}{\multicolumn{2}{|c|}{ Not statistically significant }} \\
\hline Exon $3274 \mathrm{C} / \mathrm{T}$ & $51(44.34)$ & $27(39.13)$ & & \\
\hline Exon $3274 \mathrm{~T} / \mathrm{T}$ & $16(13.91)$ & $7(10.14)$ & & \\
\hline \multicolumn{5}{|l|}{ Exon 8823} \\
\hline Exon $8823 \mathrm{C} / \mathrm{C}$ & $92(80)$ & $68(98.55)$ & \multirow{3}{*}{13.26} & \\
\hline Exon $8823 \mathrm{C} / \mathrm{T}$ & $18(15.65)$ & $1(1.44)$ & & $17.00(2.24-128.99)$ \\
\hline Exon $8823 \mathrm{~T} / \mathrm{T}$ & $5(4.34)$ & 0 & & \\
\hline \multicolumn{5}{|l|}{ Exon 15 D543N } \\
\hline Exon 15 D543N G/G & $75(65.21)$ & $52(75.36)$ & \multirow{3}{*}{\multicolumn{2}{|c|}{ Not statistically significant }} \\
\hline Exon 15 D543N G/A & $40(34.78)$ & $16(23.18)$ & & \\
\hline Exon 15 D543N A/A & 0 & $1(1.44)$ & & \\
\hline \multicolumn{5}{|l|}{$3^{\prime} U T R$} \\
\hline 3'UTR TGTG/TGTG & $65(56.52)$ & $54(78.26)$ & \multirow{3}{*}{9.6} & \\
\hline 3'UTR TGTG/del & $3(2.6)$ & 0 & & $2.76(1.40-5.46)$ \\
\hline $3^{\prime}$ UTR del/del & $47(40.86)$ & $15(21.73)$ & & \\
\hline
\end{tabular}

$\chi^{2}$ value $=$ Chi-square value with $p<0.05$ in the presence of the mutation and CL.

$\mathrm{OR}=$ odds ratio $(95 \%$ confidence interval) presence of mutation is a risk for CL.

$\mathrm{UTR}=$ untranslated region. del $=$ deletion .

TABLE 4: Genotype frequency of the NRAMP1 polymorphisms in patients requiring high doses of Glucantime (HDG).

\begin{tabular}{|c|c|c|c|c|}
\hline Genotypes & $\begin{array}{c}\text { CL-HDG (\%) } \\
n=13\end{array}$ & $\begin{array}{l}\text { CL (\%) } \\
n=115\end{array}$ & $\chi^{2}$ value & OR $(95 \% \mathrm{CI})$ \\
\hline Exon $3274 \mathrm{C} / \mathrm{C}$ & $2(12.5)$ & $48(41.73)$ & \multirow{3}{*}{22.69} & \multirow{3}{*}{$3.94(0.83-18.59)$} \\
\hline Exon $3274 \mathrm{C} / \mathrm{T}$ & $2(12.5)$ & $51(44.34)$ & & \\
\hline Exon $3274 \mathrm{~T} / \mathrm{T}$ & $9(69.23)$ & $16(13.91)$ & & \\
\hline Exon $8823 \mathrm{C} / \mathrm{C}$ & $9(69.23)$ & $92(80)$ & \multirow{3}{*}{15.43} & \multirow{3}{*}{$1.77(0.50-6.28)$} \\
\hline Exon $8823 \mathrm{C} / \mathrm{T}$ & 0 & $18(15.65)$ & & \\
\hline Exon $8823 \mathrm{~T} / \mathrm{T}$ & $4(30.76)$ & $5(4.34)$ & & \\
\hline Exon 15 D543N G/G & $10(76.92)$ & $75(65.21)$ & \multirow{3}{*}{31.75} & \multirow{3}{*}{$0.56(0.14-2.16)$} \\
\hline Exon 15 D543N G/A & 0 & $40(34.78)$ & & \\
\hline Exon 15 D543N A/A & $3(23.07)$ & 0 & & \\
\hline 3'UTR TGTG/TGTG & $8(61.53)$ & $65(56.52)$ & \multirow{3}{*}{\multicolumn{2}{|c|}{ Not statistically significant }} \\
\hline 3'UTR TGTG/del & 0 & $3(2.6)$ & & \\
\hline $3^{\prime} \mathrm{UTR} \mathrm{del} / \mathrm{del}$ & $5(38.46)$ & $47(40.86)$ & & \\
\hline
\end{tabular}

$\chi^{2}$ value $=$ Chi-square value with $p<0.05$ in the presence of the mutation and requirement of high doses of Glucantime.

$\mathrm{OR}=$ odds ratio $(95 \%$ confidence interval $) . \mathrm{UTR}=$ untranslated region. del $=$ deletion.

expression of the protein, to change the receptor of transcription factors. And finally, a 4 bp deletion in an untranslated region plays a crucial role in posttranscriptional regulation gene expression. All of the above explain the observation made in the municipality of Calakmul, Campeche state, where some people acquire CL, while others, living in the same area, under similar conditions, never developed the disease. Also, we expected to find a correlation between the polymorphisms in NRAMP1 and the tolerance presented in some patients, who need high doses of medication to heal CL.

In the present, no mutation in the promoter region $(-524$ G/C) (Table 3) was found, and 100\% of the control people and patients with LCL presented the original allele (G/G). However, Donninger and colleagues [22] found that this 
polymorphism creates a site which binds a transcription factor and then the overexpression of NRAMP1, so this mutation has been associated with protection to infection due to hyperactivity of macrophages, but in this study, this mutation was absent.

Mutation in exon $3274(\mathrm{C} / \mathrm{T})$ place was analyzed, and no significant differences in the genotype frequencies obtained were found between both groups, so mutation in exon 3 could not be associated with disease. Nevertheless Ortiz-Flores and colleagues [15] found an association between allele $274 \mathrm{C} / \mathrm{C}$ in exon 3 and susceptibility to developing CL in Mexican patients from two communities in Chiapas state, Mexico. The authors addressed that their finding differs from other studies realized in Sri Lanka and Brazil for the same diseases form, where no relation was found between this mutation and susceptibility to developing CL. The explanation for this could be that these two endemic areas in Mexico, Campeche and Chiapas states, are geographically widely separated, with different ethnic groups, and affected by different Leishmania species and probably by different variants of the same parasite species.

When exon $8(823 \mathrm{C} / \mathrm{T})$ was analyzed, our results suggested that there is a significant association between this polymorphism and CL after applying Chi-square test $\left(\chi^{2}=\right.$ $13.26 ; p<0.05)$ and the same with odds ratio test $(\mathrm{OR}=17.00$; $\mathrm{CI}=95 \%$ ), and we conclude that this mutation is a risk factor to develop CL when this mutation is present. This is because about $20 \%$ of patients with CL presented differences in this exon, unlike the control group, which merely happens in approximately $1.5 \%$ of the people of this group. Nucleotide changes in exon 3 and exon 8 in NRAMP1 gene are considered silent mutations, since the change of a nucleotide or amino acid generates a change but may actually cause disease by altering regulatory elements affecting exon RNA splicing [28, 29]. In the regular edition of RNA, the primary transcript of a gene contains sequences encoding amino acids (exons) and long noncoding sequences (introns) that should not be present in the final mRNA. In each exon there are short nucleotide sequences called Exonic Splicing Enhancer (ESE), which function as enhancers of RNA splicing, indicating the editing complex, where there are the ends of exons [30, 31]. The binding of regulatory proteins of the edition to enhancer sequences in the primary transcript makes the spliceosome directed towards both ends of the intron and cleave the primary transcript before splicing the ends of exons. Synonymous changes in a nucleotide sequence of an exon could become invisible to the enhancer sequences to protein complex of the spliceosome (due to less affinity), so an entire exon could be excluded from the final RNA. Then the secondary structure of the mRNA is affected as the stability of mRNA $[30,32]$. Additional studies suggested that decreased enzymatic activity due to reduced protein expression mediated by changes in the mRNA structures could explain the differences in the phenotype $[32,33]$. Over 50 human diseases have been associated with synonymous mutations and, in a recent survey, of 21,429 polymorphisms associated with human disease, nonsynonymous and synonymous variations were determined to have a similar probability of disease association (1.46\% and $1.26 \%$, resp.) [34].
Although the polymorphisms present in exon 3 and exon 8 have the same effect on NRAMP1 protein, in our study only mutation in exon 8 showed an association with CL. These findings agree with the association found in Morocco with VL infections, while the same polymorphism seems not to be associated with CL infection caused by Leishmania (V.) braziliensis in Brazil [16].

In relation to polymorphism in exon 15 (D543N), the polymorphism consisting in the change of $\mathrm{G}$ for $\mathrm{A}$, which generates a substitution of amino acid (aspartic acid/asparagine), affecting protein function, has been associated with susceptibility to tuberculosis in populations of West Africa and East Asia $[27,29]$. When exon 15 polymorphism was analyzed in samples from CL patients, $65.2 \%$ presented the original allele and $34.8 \%$ presented both alleles. With samples from the control group, $75 \%$ presented original allele, $23 \%$ presented both alleles, and $1.4 \%$ presented mutated allele. After statistic analysis, no significant differences between groups were found, referring to genotype frequency.

Finally, polymorphisms in $3^{\prime} \mathrm{UTR}$ region of NRAMP1 gene were analyzed to find any association between CL susceptibility and deletion of four nucleotides in this region (-TGTG). $78.26 \%$ of samples from control people presented original allele and $21.73 \%$ were homozygous for the mutated allele. In the case of patients with CL $56.52 \%$ who had the original allele, $2.6 \%$ presented both alleles and $40.86 \%$ had mutated allele. After statistic analysis significant association was found between this polymorphism and CL after applying Chi-square test $\left(\chi^{2}=9.6 ; p<0.05\right)$ and with odds ratio test $(\mathrm{OR}=2.76$; $\mathrm{CI}=95 \%)$; then there is a risk factor to develop $\mathrm{CL}$ when this mutation is present. This is because about $43 \%$ patients with CL presented differences in the $3^{\prime} \mathrm{UTR}$ region, unlike the control group, which merely occurs in about $22 \%$. The physiological effect of polymorphism in this region is not known exactly, but it is known that this region is considered gene regulatory elements [23] and its association with tuberculosis susceptibility in populations from Eastern Asia and Africa has been shown [35]. It is noteworthy that, unlike other regions in this study, patients with CL presented allele mutated in $40.86 \%$ and this allele was homozygous. In other regions, where we found a mutation, most were heterozygous. Some authors have mentioned that homozygous mutation has high relevance because the stability is greater [36] and draws attention to the high proportion of patients with mutated allele. Other authors have related the best transporter activity of NRAMP1 and its ability to generate an intraphagosomal ionic concentration (which allow survival and reproduction of microorganisms) and the presence of mutated allele and even heterozygote alleles [37]. This mutated allele also causes an appropriate level of $\mathrm{Fe}^{+2}$ that allows development of microorganisms because it has been suggested that affected NRAMP1 reduces iron release from macrophages. Then iron accumulates in the liver and spleen when erythrophagocytosis happens and when there are changes in level of iron and other metals, ROS- (Reactive Oxygen Species-) regulated signaling is altered, in the same way as inflammatory pathway activation, a very important antimicrobial mechanism [38]. 
In some studies, where macrophages with a mutation in NRAMP1 protein were infected with mycobacteria, the ability to process antigens was loose, affecting the CD4 lymphocytes activity and therefore the Th1 response, promoting a Th2 profile and the progression of tuberculosis $[27,35]$. For the case of leishmaniasis diseases, a similar model is proposed, due to be an intracellular pathogen. Susceptibility to CL has been associated with several polymorphic genes, including NRAMP1 (SLC11A1) in Brazil. Another study realized in a Mexican endemic area (Chiapas state, Mexico) with the object related to polymorphism of different genes, including $N R A M P 1$, with different forms of leishmaniasis diseases, showed that, for this population and endemic area, none of SLC11A1 alleles analyzed (they chose seven polymorphisms of this gene) had no relation with susceptibility to CL, except for one genotype $(\mathrm{C} / \mathrm{C})$ in exon $3(274 \mathrm{C} / \mathrm{T})$ which was associated with $\mathrm{CL}$ susceptibility [15]. This differs from results obtained with patients from Campeche state, where exon 3 polymorphisms in NRAMP1 gene and CL susceptibility were not related. Maybe as mentioned before, the differences in the ethnic group, Leishmania species and geographical environment, may be the explanation for the results from Calakmul foci.

When the analysis was made with samples from patients with CL which needed higher doses of Glucantime than the mean of 25 ampules used by Vargas-Gonzalez [39], the association between polymorphisms (homo- and heterozygote mutation) in exon 3 caught our attention; 11 samples of 13 patients, which needed high doses of Glucantime, had a mutation in exon 3 and presented the allele $(274 \mathrm{C} / \mathrm{T})$. We made a statistically important relationship between the presence of this allele in a patient and the need for high doses of Glucantime; the relative risk was found ( $\mathrm{OR}=3.94)$ (Table 4). Two samples had the original allele. Analysis of exon 8 and exon 15 shows association with risk of needing large doses of medication, but with OR values lower than those obtained in exon 3. When the UTR region for the same samples was realized, there was no association between high doses of treatment and polymorphisms in this region. Some samples showed an extra mutation in some other exons in addition to those existing in exon 3.

The correlation between the number of lesions and the amount of drug administered was also analyzed [results not shown] because patients who required high doses of Glucantime were the patients with many lesions, then 25 samples were analyzed and 22 presented, at least, one mutation in any of five regions of this study, and 3 patients had no mutation. Of 22 patients, 13 presented mutation in exon 3 and 2 patients presented mutation in exon $8 ; 3$ patients had mutation in exon 15 and 2 presented mutation in $3^{\prime}$ UTR region, unfortunately without statistical significance. There is clearly an alteration in NRAMP1 protein, affecting innate immunity, so the patient does not stop the growth of the pathogen and develops the disease again. Similarly, patients who had a single lesion were analyzed, and results showed that this group of patients at least had one mutation in some of the regions of this study, but no significant association was found.

\section{Conclusions}

In the case of leishmaniasis diseases, to date, there are no effective chemoprophylaxis measures as in malaria. Several groups are working to produce protective vaccines; others are looking for better treatment, less toxication, and more accessible. In Mexico there are no mechanisms for the prevention and control of leishmaniasis in short term. Unfortunately, new cases of CL arise in farming communities, who are looking for new lands to work in the jungle, where the life cycle of this parasite has prevailed. And as it was demonstrated in the population of this study, the probabilities of developing CL are higher if a person is susceptible due to mutation in exon 8 of NRAMP1 or a deletion in $3^{\prime} U T R$.

Other polymorphisms of NRAMP1 remain to be investigated in the same community and extend the study to other endemic areas in Mexico and what relation it has with CL expression. In the same way, genetic causes of the different response to drug must be investigated in depth, looking for the pharmacological activity protein genes.

\section{Disclosure}

Amalia Monroy-Ostria was fellow of CONACyT, EDI, COFAA, Mexico. Mario Eugenio Cancino-Díaz is a fellow of SNI, COFAA, EDI, Mexico. Mirsha Pamela HernándezRivera was fellow of CONACyT, Mexico.

\section{Competing Interests}

The authors declare that there are no competing interests regarding the publication of this paper.

\section{Acknowledgments}

The authors thank the people of Calakmul, Campeche, who contributed to this study. Financial support for this research was provided by Direccion de Servicio Social y Egresados, Instituto Politécnico Nacional, Mexico, and Servicios de Salud del H. Ayuntamiento de Calakmul, Campeche.

\section{References}

[1] I. Cruz, A. Millet, E. Carrillo et al., "An approach for interlaboratory comparison of conventional and real-time PCR assays for diagnosis of human leishmaniasis," Experimental Parasitology, vol. 134, no. 3, pp. 281-289, 2013.

[2] J. Alvar, I. D. Vélez, C. Bern et al., "Leishmaniasis worldwide and global estimates of its incidence," PLOS ONE, vol. 7, no. 5, article e35671, 2012.

[3] M. D. J. Rovirosa-Hernández, L. Cortes-Ortíz, F. GarcíaOrduña et al., "Seroprevalence of Trypanosoma cruzi and Leishmania mexicana in free-ranging howler monkeys in southeastern Mexico," American Journal of Primatology, vol. 75, no. 2, pp. 161-169, 2013.

[4] I. Kevric, M. A. Cappel, and J. H. Keeling, "New world and old world leishmania infections: a practical review," Dermatologic Clinics, vol. 33, no. 3, pp. 579-593, 2015. 
[5] O. Velasco Castrejon, "Leishmaniasis in Mexico," Revista Latinoamericana de Microbiología, vol. 29, no. 2, pp. 119-126, 1987.

[6] O. Hernandez-Montes, A. Monroy-Ostria, S. McCann, and D. C. Barker, "Identification of Mexican Leishmania species by analysis of PCR amplified DNA," Acta Tropica, vol. 71, no. 2, pp. 139-153, 1998.

[7] G. Sanchez-Tejeda, N. Rodríguez, C. I. Parra, O. HernandezMontes, D. C. Barker, and A. Monroy-Ostria, "Cutaneous leishmaniasis caused by members of Leishmania braziliensis complex in Nayarit, State of Mexico," Memorias do Instituto Oswaldo Cruz, vol. 96, no. 1, pp. 15-19, 2001.

[8] A. Monroy-Ostria, O. Hernandez-Montes, and D. C. Barker, "Aetiology of visceral leishmaniasis in Mexico," Acta Tropica, vol. 75, no. 2, pp. 155-161, 2000.

[9] F. J. Andrade-Narváez, A. Vargas-González, S. B. Canto-Lara, and A. G. Damián-Centeno, "Clinical picture of cutaneous leishmaniases due to Leishmania (Leishmania) mexicana in the Yucatan peninsula, Mexico," Memórias do Instituto Oswaldo Cruz, vol. 96, no. 2, pp. 163-167, 2001.

[10] J. M. Blackwell, S. Searle, T. Goswami, and E. N. Miller, "Understanding the multiple functions of Nrampl," Microbes and Infection, vol. 2, no. 3, pp. 317-321, 2000.

[11] J. M. Blackwell, T. Goswami, C. A. W. Evans et al., "SLC11A1 (formerly NRAMP1) and disease resistance," Cellular Microbiology, vol. 3, no. 12, pp. 773-784, 2001.

[12] J. R. Forbes and P. Gros, "Divalent-metal transport by NRAMP proteins at the interface of host-pathogen interactions," Trends in Microbiology, vol. 9, no. 8, pp. 397-403, 2001.

[13] A. Awomoyi, G. Sirugo, M. J. Newport, and S. Tishkoff, "Global distribution of a novel trinucleotide microsatellite polymorphism (ATA)n in intron 8 of the SLC11A1 gene and susceptibility to pulmonary tuberculosis," International Journal of Immunogenetics, vol. 33, no. 1, pp. 11-15, 2006.

[14] N. S. Archer, N. T. Nassif, and B. A. O’Brien, “Genetic variants of SLC11A1 are associated with both autoimmune and infectious diseases: systematic review and meta-analysis," Genes and Immunity, vol. 16, no. 4, pp. 275-283, 2015.

[15] A. Ortiz-Flores, G. De la Rosa-López, B. Zavaleta-Villa et al., "Association of leishmaniasis with TNF alpha promoter and SLC11A1 gene polymorphisms in patients of two endemic areas in Mexico," Microbes and Infection, vol. 17, no. 5, pp. 387-394, 2016.

[16] L. Castellucci, S. E. Jamieson, E. N. Miller et al., "CXCR1 and SLC11A1 polymorphisms affect susceptibility to cutaneous leishmaniasis in Brazil: a case-control and family-based study," BMC Medical Genetics, vol. 11, article 10, 2010.

[17] H. S. Mohamed, M. E. Ibrahim, E. N. Miller et al., "SLC11A1 (formerly NRAMP1) and susceptibility to visceral leishmaniasis in the Sudan," European Journal of Human Genetics, vol. 12, no. 1, pp. 66-74, 2004.

[18] R. Ejghal, M. Hida, M. L. Idrissi, A. E. Hessni, and M. Lemrani, "SLC11A1 polymorphisms and susceptibility to visceral leishmaniasis in Moroccan patients," Acta Tropica, vol. 140, pp. 130-136, 2014.

[19] M. P. Hernandez-Rivera, O. Hernandez-Montes, A. ChinasPerez et al., "Study of cutaneous leishmaniasis in the State of Campeche (Yucatan Peninsula), Mexico, over a period of two years," Salud Pública de México, vol. 57, no. 1, pp. 58-65, 2015.

[20] R. K. Saiki, D. H. Gelfand, S. Stoffel et al., "Primer-directed enzymatic amplification of DNA with a thermostable DNA polymerase," Science, vol. 239, no. 4839, pp. 487-491, 1988.
[21] J. Liu, T. M. Fujiwara, N. T. Buu et al., "Identification of polymorphisms and sequence variants in the human homologue of the mouse natural resistance-associated macrophage protein gene," American Journal of Human Genetics, vol. 56, no. 4, pp. 845-853, 1995.

[22] H. Donninger, T. J. Cashmore, T. Scriba, D. C. Petersen, E. Janse van Rensburg, and V. M. Hayes, "Functional analysis of novel SLC11A1 (NRAMP1) promoter variants in susceptibility to HIV1," Journal of Medical Genetics, vol. 41, no. 4, article e49, 2004.

[23] Y. S. Yang, S. J. Kim, J. W. Kim, and E.-M. Koh, "NRAMP1 gene polymorphisms in patients with Rheumatoid Arthritis in Koreans," Journal of Korean Medical Science, vol. 15, no. 1, pp. 83-87, 2000.

[24] K. Ouchi, Y. Suzuki, T. Shirakawa, and F. Kishi, "Polymorphism of SLC11A1 (formerly NRAMP1) gene confers susceptibility to Kawasaki disease," Journal of Infectious Diseases, vol. 187, no. 2, pp. 326-329, 2003.

[25] R. Bellamy, "The natural resistance-associated macrophage protein and susceptibility to intracellular pathogens," Microbes and Infection, vol. 1, no. 1, pp. 23-27, 1999.

[26] M. J. Maliarik, K. M. Chen, R. G. Sheffer et al., “The natural resistance-associated macrophage protein gene in African Americans with sarcoidosis," American Journal of Respiratory Cell and Molecular Biology, vol. 22, no. 6, pp. 672-675, 2000.

[27] W. Zhang, L. Shao, X. Weng et al., "Variants of the natural resistance-associated macrophage protein 1 gene (NRAMP1) are associated with severe forms of pulmonary tuberculosis," Clinical Infectious Diseases, vol. 40, no. 9, pp. 1232-1236, 2005.

[28] I. D’Souza, P. Poorkaj, M. Hong et al., "Missense and silent tau gene mutations cause frontotemporal dementia with parkinsonism-chromosome 17 type, by affecting multiple alternative RNA splicing regulatory elements," Proceedings of the National Academy of Sciences of the United States of America, vol. 96, no. 10, pp. 5598-5603, 1999.

[29] C. L. Lorson, E. Hahnen, E. J. Androphy, and B. Wirth, "A single nucleotide in the SMN gene regulates splicing and is responsible for spinal muscular atrophy," Proceedings of the National Academy of Sciences of the United States of America, vol. 96, no. 11, pp. 6307-6311, 1999.

[30] J. V. Chamary and L. D. Hurst, "The price of silent mutations," Scientific American, vol. 300, no. 6, pp. 46-53, 2009.

[31] Y. Lee and D. C. Rio, "Mechanisms and regulation of alternative Pre-mRNA splicing," Annual Review of Biochemistry, vol. 84, pp. 291-323, 2015.

[32] Z. E. Sauna and C. Kimchi-Sarfaty, "Synonymous mutations as a cause of human genetic disease," in $e L S$, John Wiley \& Sons, Chichester, UK, 2013.

[33] L. Cartegni, S. L. Chew, and A. R. Krainer, "Listening to silence and understanding nonsense: exonic mutations that affect splicing," Nature Reviews Genetics, vol. 3, no. 4, pp. 285298, 2002.

[34] R. C. Hunt, V. L. Simhadri, M. Iandoli, Z. E. Sauna, and C. Kimchi-Sarfaty, "Exposing synonymous mutations," Trends in Genetics, vol. 30, no. 7, pp. 308-321, 2014.

[35] J. Jin, L. Sun, W. Jiao et al., "SLC11A1 (formerly NRAMP1) gene polymorphisms associated with pediatric tuberculosis in China," Clinical Infectious Diseases, vol. 48, no. 6, pp. 733-738, 2009.

[36] P. M. Altrock, A. Traulsen, and F. A. Reed, "Stability properties of underdominance in finite subdivided populations," PLoS Computational Biology, vol. 7, no. 11, article e1002260, 2011. 
[37] S. J. Meisner, S. Mucklow, G. Warner, S. O. Sow, C. Lienhardt, and A. V. S. Hill, "Association of NRAMP1 polymorphism with leprosy type but not susceptibility to leprosy per se in west Africans," The American Journal of Tropical Medicine and Hygiene, vol. 65, no. 6, pp. 733-735, 2001.

[38] M. Wessling-Resnick, "Nrampl and other transporters involved in metal withholding during infection," The Journal of Biological Chemistry, vol. 290, no. 31, pp. 18984-18990, 2015.

[39] A. Vargas-Gonzalez, S. B. Canto-Lara, A. G. Damian-Centeno, and F. J. Andrade-Narvaez, "Response of cutaneous leishmaniasis (chiclero's ulcer) to treatment with meglumine antimoniate in southeast Mexico," American Journal of Tropical Medicine and Hygiene, vol. 61, no. 6, pp. 960-963, 1999. 


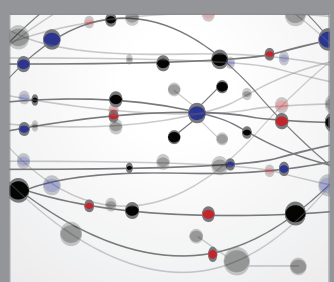

The Scientific World Journal
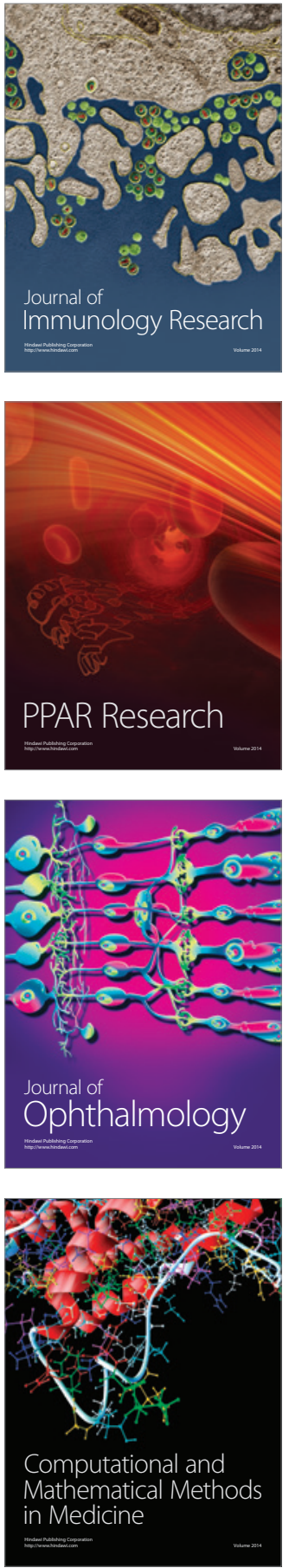

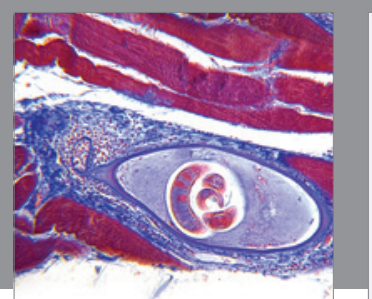

Gastroenterology Research and Practice

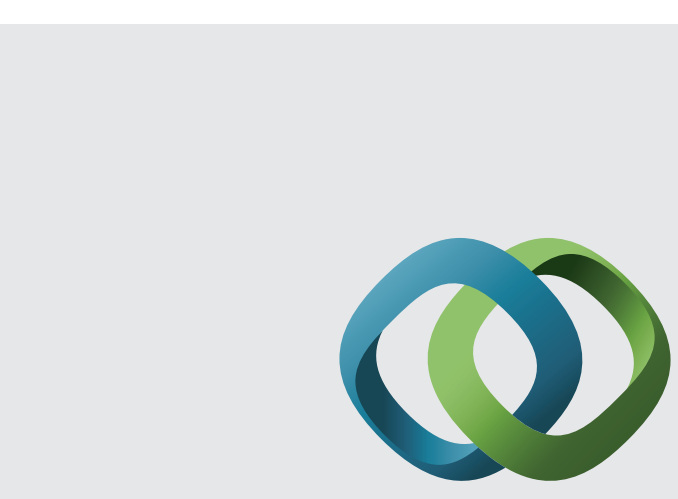

\section{Hindawi}

Submit your manuscripts at

http://www.hindawi.com
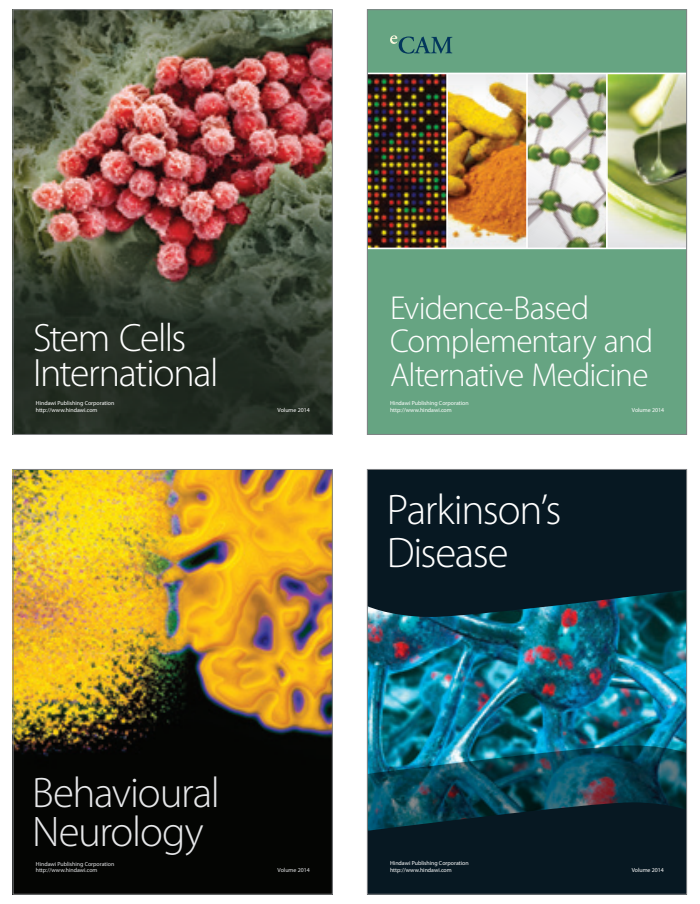
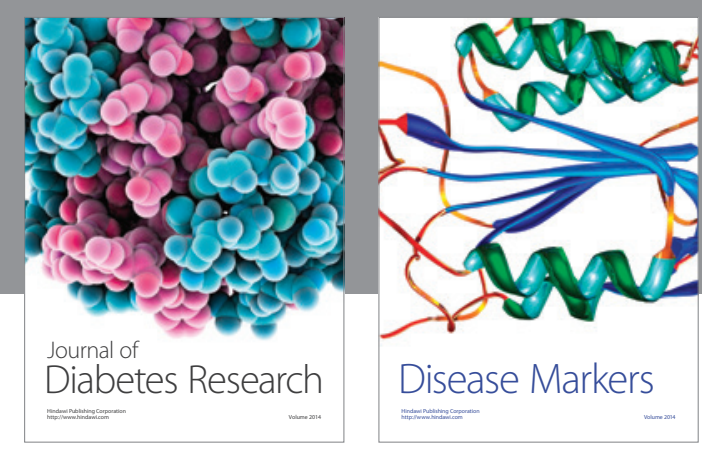

Disease Markers
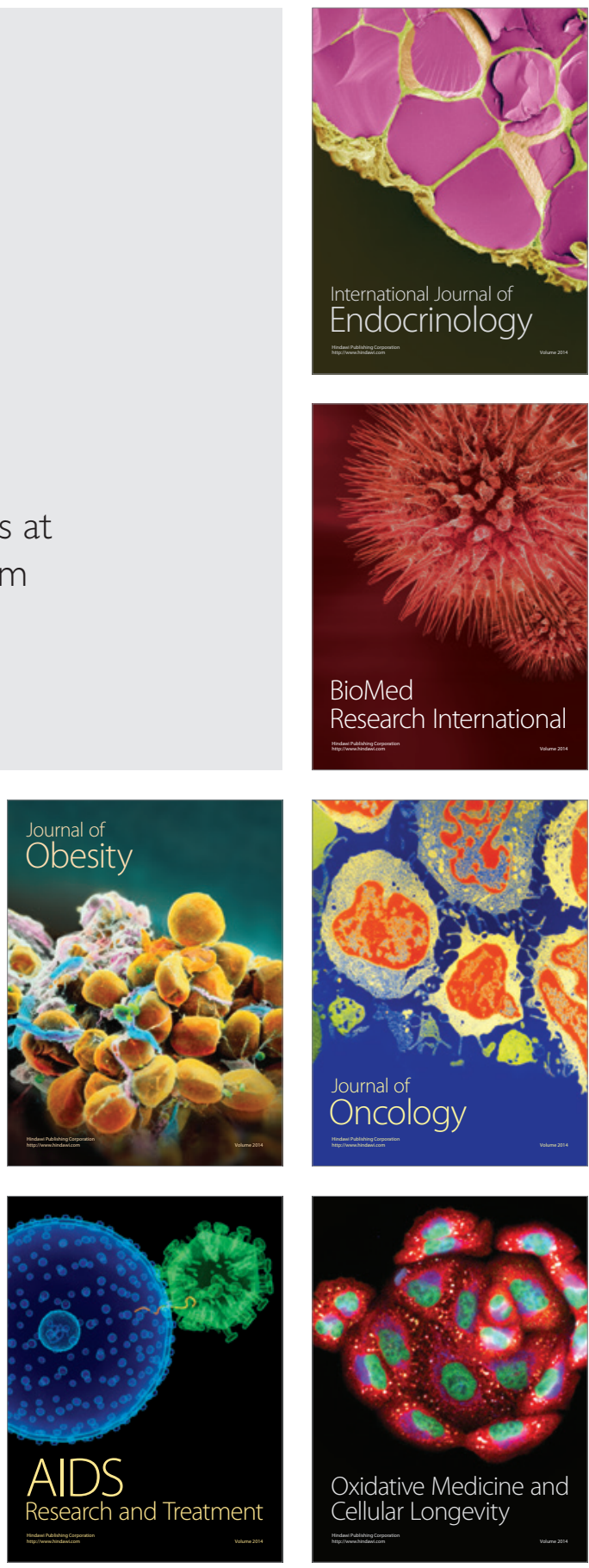